\title{
INTERLOCUÇÕES ENTRE SOCIOLOGIA DA INFÂNCIA E PROJETOS DE TRABALHO: A CRIANÇA COMO PROTAGONISTA NO PROCESSO DE CONSTRUÇÃO DO CONHECIMENTO.
}

Indira Aparecida Santana Aragão Favareto

Universidade Estadual Paulista - UNESP, PPGE - Programa de Pós-Graduação em Educação, Presidente Prudente, SP.

\section{RESUMO}

Este artigo busca fazer relações entre a sociologia da infância e os projetos de trabalho onde o objetivo central é tornar a criança centro do processo de construção do conhecimento, considerando-a como um cidadão de direitos e deveres que produz cultura e tem formas especificas de agir sobre o mundo. Os projetos de trabalho e a sociologia da infância contribuem com o trabalho do professor na medida em que priorizam práticas significativas tornando a escola cada vez mais próxima da vida da criança e permitindo que ela experimente, crie, questione, aprenda a trabalhar em grupo e seja sujeito ativo no seu processo de aprendizagem.

Palavras Chaves: Educação Infantil, Sociologia da Infância, Projetos de Trabalho. Protagonismo Infantil, Trabalho Docente.

\section{INTERLOCUTIONS BETWEEN SOCIOLOGY OF CHILDHOOD AND WORK PROJECT: CHILD INVOLVEMENT IN THE PROCESS OF KNOWLEDGE CONSTRUCTION.}

\begin{abstract}
This article aims to make relations between the sociology of childhood and work projects where the main objective is to make the child center of knowledge building process, considering it as a citizen of rights and duties that produces culture and has specific forms to act on the world. The work projects and the sociology of childhood contribute to the teacher's work in that prioritize significant practical making ever closer school child's life and allowing it to experiment, create, question, learn to work together and be active subject in the learning process.
\end{abstract}

Keywords: Early Childhood Education, Sociology of Childhood Work Projects. Protagonism Children, Teaching Work. 


\section{INTRODUÇÃO}

Nas ultimas décadas alavancaram-se inúmeras discussões sobre como oferecer um atendimento de qualidade as crianças que frequentam a Educação Infantil, desta forma a infância ganhou destaque exigindo atenção das políticas publicas e também de estudos que pudessem contribuir com o trabalho dos professores, que atuam nas instituições de Educação Infantil.

A sociologia da infância com o paradigma da infância como construção social, considerando as crianças sujeitos que interagem com a sociedade com uma forma própria e singular de ver e agir sobre o mundo, e os projetos de trabalho com a concepção de que o currículo da escola pode se aproximar da vida dos alunos, fazendo que as crianças participem cada vez mais do processo de aprendizagem e sejam sujeitos na construção de seu conhecimento. Esta interligação das duas concepções colabora com o trabalho do professor no sentido que as atividades propostas em sala de aula tenham o objetivo de fazer com que as crianças explorem, experimentem, questionem, interajam e sejam protagonistas de sua aprendizagem.

A partir do início da década de 80 devido a Constituição Federal de 1988 (BRASIL, 1988), em decorrência de vários movimentos sociais, principalmente de mulheres trabalhadoras, que precisavam trabalhar para ajudar no sustento da família e precisam de um local adequado para deixarem seus filhos, a criança torna-se sujeito de direitos, e a educação das crianças de 0 a 6 anos passa a ser um direito de todo cidadão e dever do estado, sendo assim, vários debates a cerca de um currículo para a educação infantil, começaram a alavancar e acentuar reflexões em razão de um projeto pedagógico que abarcasse a educação da criança de 0 a 6 anos.

Em 1996 a Lei de Diretrizes e Bases da Educação afirma em seu artigo 29 que "A educação infantil tem como finalidade o desenvolvimento integral das crianças com até seis anos de idade, em seu aspecto físico, psicológico, intelectual e social". A partir daí a Educação Infantil percorreu novos rumos onde começaram iniciando uma maior reflexão sobre a serem refletidos os aspectos educativos existentes no cotidiano das instituições de Educação Infantil.

Através da Lei de Diretrizes e Bases da Educação Nacional (BRASIL, 1996) a Educação Infantil passou a ser inserida no sistema de ensino, o que trouxe um avanço significativo a educação das crianças pequenas, dando a elas a oportunidade de serem educadas e cuidadas em ambientes propícios para o seu desenvolvimento integral, outro avanço de extrema importância, foi que a partir da LDB (1996) a educação infantil passou a ser considerada como primeira etapa da educação básica, evidenciando ainda mais sua importância para a educação e cuidados das crianças de zero a seis anos de idade.

Neste momento de muitas discussões e reflexões, a sociologia da infância também por volta dos anos $80 \mathrm{fez}$ emergir uma nova concepção de que a infância é uma construção social. Deste modo as crianças são atores sociais que produzem cultura e uma forma própria de agir sobre o mundo.

A infância é, simultaneamente, uma categoria social, do tipo geracional, e um grupo social de sujeitos ativos, que interpretam e agem no mundo. Nessa ação estruturam e estabelecem padrões culturais. As culturas infantis constituem, com efeito o mais importante aspecto na diferenciação da infância. (SARMENTO, 2007, p.10).

As crianças são atores sociais que interagem com o mundo em que vivem de forma própria e singular, podemos considerar que com as diversas mudanças sociais existem várias infâncias, de acordo com (SARMENTO, 2004, p.10) "as crianças são também seres sociais e, como tais, distribuem-se pelos diversos modos de estratificação social: a classe social, a etnia a que pertencem, a raça, o gênero, a região do globo onde vivem. Os diferentes espaços estruturais diferenciam profundamente as crianças. 
A infância é uma construção social, que se relaciona a condição de vida de uma criança, e qualidade de seus primeiros anos. Portanto a Educação Infantil é uma etapa muito importante da vida escolar das crianças que além de se preocupar com a aprendizagem deve possibilitar condições para o seu pleno desenvolvimento.

É neste contexto que a sociologia da infância pressupõe que as crianças sejam reconhecidas como atores sociais considerando-as como cidadãos de direitos e os projetos de trabalho contribuem para que a prática do professor aproxime os conteúdos escolares da vida das crianças tornando sua aprendizagem mais significativa, as duas concepções compartilham da ideia de tornar a criança centro do processo educativo para que elas participem e reflitam sobre aquilo que estão aprendendo.

Este artigo busca discutir a relação existente entre a sociologia da infância e os projetos de trabalho, onde o objetivo principal das duas concepções é tornar as crianças centro do processo de aprendizagem, para que elas possam participar de modo ativo e que sejam consideradas como protagonistas do seu desenvolvimento, retirando do trabalho dos professores a visão adultocentrica, e com isso dando maior visibilidade as culturas infantis.

\section{METODOLOGIA}

O presente estudo se enquadra nos princípios da pesquisa qualitativa, que prima pela qualidade e fidedignidade dos resultados. Deste modo, na pesquisa qualitativa, o pesquisador está em constante relação com seu objeto de estudo. Conforme afirmam Bogdan e Biklen (1994, p.49):

A abordagem de investigação qualitativa exige que o mundo seja examinado com a ideia de que nada é trivial, que tudo tem potencial para constituir uma pista que nos permita estabelecer uma compreensão mais esclarecedora do nosso objeto de estudo.

A pesquisa caracterizada como bibliográfica segundo destaca Gil (2010, p. 29), “[...] é elaborada com base em material já publicado". E tem como corpus de análise referencial teórico publicado por autores que tratam da sociologia da infância com isso, procuramos compreender a relação da sociologia da infância com os projetos de trabalho em práticas que tornam a criança como protagonista e sujeito ativo no seu processo de construção de conhecimento.

\section{RESULTADOS}

A Educação Infantil é um espaço privilegiado rico em interações, sua função é oferecer condições plenas para o desenvolvimento das crianças de modo que estabeleçam relações entre seus pares, se desenvolvam a aprendam a conviver com o outro.

Para Barbosa e Horn (2008) a função pedagógica das Instituições de Educação Infantil (IEI) é tornar a criança centro do planejamento curricular, com isso, deve-se valorizar a autonomia, criatividade, proporcionar atividades que fortaleçam a autoestima, e seus vínculos afetivos.

A sociologia da infância tem como objetivo principal de seus estudos evidenciar a criança como um ser social e histórico para que nós educadores possamos enxergá-la de forma própria rompendo com o adultocentrismo.

Os projetos de trabalho na perspectiva de Hernández e Ventura (1998) estão vinculados a uma perspectiva do conhecimento globalizado e são uma forma de organizar os conteúdos escolares relacionando-os com as necessidades dos sujeitos, permitindo que o conhecimento seja elaborado de forma coletiva, partindo de indagações e questionamentos que são do interesse das crianças e comunidade escolar. Desta forma, as situações de aprendizagem se tornam significativas, pois as próprias crianças participam ativamente de todo o processo de construção do conhecimento. 
Trabalhar com projetos possibilita tornar as crianças centro do processo educativo, considerando seus conhecimentos prévios de modo que as crianças elaborem sentido ao que estão aprendendo, e tenham a oportunidade de pesquisar, selecionar, informações, argumentar, pensar e refletir coletivamente.

Os projetos de trabalho relacionan-se com a sociologia da infância na medida em que buscam tornar a criança sujeito de sua aprendizagem para que possam agir sobre seu conhecimento, tornando os conteúdos escolares mais próximos da vida das crianças.

\section{DISCUSSÃO}

A Educação Infantil considerada como primeira etapa da educação básica tem como função respeitar as especificidades da infância, considerando seus saberes e oferecendo-lhes experiências diversificadas, que contribuam com seu desenvolvimento.

As Instituições de Educação Infantil precisam organizar um cotidiano de situações agradáveis, estimulantes, que desafiem o que cada criança e seu grupo de crianças já sabem sem ameaçar sua autoestima nem promover competitividade, ampliando as possibilidades infantis de cuidar e ser cuidada, de se expressar, comunicar e criar, de organizar pensamentos e ideias, de conviver, brincar e trabalhar em grupo, de ter iniciativa e buscar soluções para os problemas e conflitos que se apresentam as mais diferentes idades, e lhes possibilitem apropriar-se de diferentes idades, e Ihes possibilitem apropriar-se de diferentes linguagens e saberes que circulam em nossa sociedade, selecionados pelo valor formativo que possuem em relação aos objetivos definidos em seu Projeto Político Pedagógico. (BRASIL, 2009, p.09).

A função da educação é possibilitar aos alunos a capacidade de agir em todos os âmbitos da sociedade, deste modo os projetos de trabalho permitem que os conteúdos se aproximem da realidade dos alunos. Segundo Hernández e Ventura (1998), qualquer tema, por mais complexo que seja, pode ser explorado em classe. Com isso o currículo não se torna algo fragmentado.

A escuta das crianças, sua participação em todas as atividades realizadas na instituição é um fator de grande relevância para se garantir a cidadania infantil.

As crianças se encontram em um mundo estruturado por relações materiais, sociais, emocionais e cognitivas que organizam suas vidas cotidianas e suas relações com o mundo. É nesse contexto que elas vão constituindo suas identidades como crianças e como membros de um grupo social. Não devem, todavia, ser vistas como sujeitos passivos que apenas incorporam a cultura adulta que lhes é imposta, mas como sujeitos que interagindo com esse mundo, criam formas próprias de compreensão e de ação sobre a realidade. (BORBA, 2007, p.38-39).

Os projetos de trabalho compartilham com a sociologia da infância o anseio de tornar a escola mais significativa para as crianças, fazendo com que ouçam mais seus desejos, histórias, culturas, e tornando suas vivências parte do currículo da escola.

Corroborando com (MORAES, 2005, p.23) que aponta:

Pelo projeto, a participação da criança é incentivada, pois o tema em discussão é do seu interesse, faz parte de sua vida, de seu mundo. Estudar questões que envolvam a realidade da criança ajuda na compreensão sobre a realidade, sobre os fenômenos e experiência diversas. Projetos que 
investigam temas que são conhecidos pelas crianças, que fazem parte de suas vidas, oferecem á criança maior possibilidade de participação e decisão sobre o que desejam pesquisar, sendo profundamente interessante para elas.

$\mathrm{Na}$ Educação Infantil as crianças partilham de espaços e tempos com diferentes crianças e adultos, criando hábitos, costumes e um sentimento de pertença ao grupo. É deste modo que se estabelecem as culturas das infâncias que de acordo com (BORBA, 2007, p.39) "As culturas da infância podem ser vistas como construção coletiva que se faz através da ação social das crianças frente ás estruturas sociais e institucionais em que estão inseridas".

As crianças agem sobre o mundo, desenvolvendo culturas e identidades próprias, os projetos de trabalho pretendem fazer com que as culturas infantis sejam consideradas no cotidiano da escola e aprendizagem se torne cheia de significado.

Para haver aprendizagem, é preciso organizar um currículo que seja significativo para as crianças e também para os professores. Um currículo não pode ser a repetição contínua de conteúdos, como uma ladainha que se repete infindavelmente no mesmo ritmo, no mesmo tom, não importando quem ouça, quem observe ou o que se aprende. Afinal, sabese que o conhecimento não é verdade imutável, mas algo transitório, inacabado, imperfeito e em contínua pesquisa. Os projetos abrem a possibilidade de aprender os diferentes conhecimentos construídos na história da humanidade de modo relacional e não-linear, propiciando ás crianças aprender através de múltiplas linguagens, ao mesmo tempo em que lhes proporcionam a reconstrução do que já foi aprendido. (BARBOSA, HORN, 2008, p.35).

Ao fazermos interlocuções da sociologia da infância com os projetos de trabalho podemos perceber que as duas concepções são importantes para que as crianças sejam consideradas como sujeitos ativos do seu próprio desenvolvimento e do seu processo de conhecimento.

\section{CONCLUSÃO}

A sociologia da infância propiciou um novo olhar sobre a criança, tornando-as como um grupo social que constroem formas específicas de agir sobre o mundo produzindo culturas. É muito importante compreendermos as crianças como agentes ativos na constituição de suas vidas, e na produção do mundo dos adultos.

De acordo com (BORBA, 2007, p.40):

As culturas infantis não são, portanto, pré-existentes ás crianças, e não funcionam como algo estático que elas levam consigo para guiar seus comportamentos. Ao contrário, constituem um processo produzido e partilhado na medida em que as crianças participam coletivamente de uma experiência social.

Os projetos de trabalho priorizam o trabalho coletivo, dando às crianças a oportunidade de participarem ativamente do processo de construção do conhecimento, pois abordam temas e problemas que vão além das disciplinas escolares e que consideram os contextos culturais e experiências de vida das crianças.A proposta de trabalho com projetos possibilita o envolvimento das crianças em temas que despertam interesse e fazem parte de seu 
cotidiano desenvolvendo a capacidade de buscar e selecionar informações e produzir conhecimento de forma criativa.

A Educação Infantil deve ser considerada como um campo de diversas possibilidades, as experiências realizadas na instituição devem priorizar situações significativas que desenvolvam a identidade pessoal, autoestima confiança e autonomia.

As práticas pedagógicas devem garantir o direito de ação e participação das crianças, desconsiderando a concepção de que é preciso prepará-las para um tempo futuro e sim considerálas como um cidadão do hoje, dando-lhes direito a palavra, e reconhecendo-as como produtora de

significados. É deste modo que os projetos de trabalho compartilham com as ideias da sociologia da infância proporcionando as crianças uma participação intensa e ativa no processo de construção do conhecimento, tornando-as como centro de sua aprendizagem e produtoras de culturas.

\section{REFERÊNCIAS}

BARBOSA, M. C. S.; HORN, M. G. S. Projetos Pedagógicos na Educação Infantil. Porto Alegre: Artmed, 2008.

BORBA, A.M. As Culturas da Infância nos espaços-tempos do brincar: estratégias de participação e construção da ordem social em um grupo de crianças de 4-6 anos. Momento: Diálogos em Educação. Rio Grande do Sul. n.1, v.8, p. 35-50. 2007.

BOGDAN, R.C.; BIKLEN, S. K. Investigação Qualitativa em Educação: uma introdução é teoria e aos métodos. Porto, Porto Editora, 1994.

BRASIL. Senado Federal. Constituição da República Federativa do Brasil. Brasília, Imprensa Oficial, Brasília: 1998.

. Lei de Diretrizes e Bases da Educação Nacional. Lei n. 9394 promulgada em 20 de dezembro de 1996. São Paulo: Roma Victor ed., 2007.

20/2009.

. Revisão das Diretrizes Curriculares Nacionais para a Educação Infantil. Parecer CNE/CEB no

. Resolução CEB n.o 5 de 17 de Dezembro de 2009. Fixa as Diretrizes Curriculares Nacionais para a Educação Infantil.

GIL, A.C. Como elaborar projetos de pesquisa. 5. Ed. São Paulo: Atlas, 2010.

HERNÁNDEZ, F.; VENTURA, M. A organização do currículo por projetos de trabalho: o conhecimento é um caleidoscópio. Trad. Jussara Haubert Rodrigues Porto Alegre: Artmed, 1998.

MORAES, L. A. Y de. O Trabalho com projetos na Educação Infantil. 2005.82f. Dissertação (Mestrado em Educação) - Centro de Educação e Ciências Humanas, Universidade Federal de São Carlos, São Carlos, 2005.

SARMENTO, Manuel Jacinto (2007). "Visibilidade Social e Estudo da Infância", in Vasconcellos, Vera M. R. e Sarmento, Manuel Jacinto (org.) (2007). Infância (in)Visível. Araraquara. Junqueira \& Marin (25-49). 
SARMENTO, Manuel Jacinto (2004). "As Culturas da Infância nas Encruzilhadas da 2a Modernidade", In M. J. Sarmento e A B. Cerisara (Org), Crianças e Miúdos. Perspectivas SócioPedagógicas da Infância e Educação. Porto. 